\title{
COMO AS ESCOLAS FAZEM AS POLÍTICAS: ATUAÇÃO EM ESCOLAS SECUNDÁRIAS
}

BALL, Stephen J.; MAGUIRRE, Meg; BRAUN, Annette. Como as escolas fazem as políticas: atuação em escolas secundárias. Ponta Grossa: Editora UEPG, 2016, 230p.

Mauricio de Sousa ${ }^{\mathrm{I}}$

${ }^{\mathrm{I}}$ Universidade Estadual de Campinas, São Paulo - Brasil. E-mail: sousama72@gmail.com

Neste momento, em que vivemos uma grande instabilidade das instituições políticas do país e "deterioração" da economia nacional, surgem diversas propostas políticas, econômicas e sociais como "salvadoras" dessa "desordem" institucionalizada. A educação não ficou de fora desse "caos criado" e, as "velhas" propostas, conservadoras e neoliberais, para qualidade da educação pública são retomadas com mais força. Apenas para citarmos duas destas propostas, que estão sendo (im) postas como redentoras da educação pública brasileira, temos: a reforma do ensino médio e a base nacional comum curricular, fundamentadas por uma política de avaliação externa.

Neste processo de apresentação destas propostas "salvadoras" da educação brasileira, temos claro que as escolas e os sujeitos políticos que a compõem serão os últimos a serem ouvidos. Nesse sentido, a obra de Stephen J. Ball, Meg Maguire e Annete Braun, publicada em 2012, na Inglaterra, e traduzida agora para o português, com o título - Como as escolas fazem as políticas: atuação em escolas secundárias - traz como foco principal de discussão, as políticas educacionais a partir das escolas, ou seja, "como as escolas "fazem" política, 
especificamente como as políticas tornam-se "vivas" e atuantes (ou não) nas escolas" (BALL, S.; MAGUIRRE, M.; BRAUN, A., 2016, p. 12).

Essa obra, dividida em sete capítulos, se apresenta como um grande desafio, não apenas com o propósito de rever o conceito de política, mas também, proporcionar novos instrumentos de análise das políticas educacionais, no espaço escolar, e avançar na construção de uma teoria fundamentada sobre a atuação política (policy enactment) ${ }^{1}$. Para isso, os autores realizaram um estudo de caso em quatro escolas públicas inglesas, durante dois anos e meio, em que coletaram dados, observaram, entrevistaram, registraram e analisaram como as políticas educacionais são atuadas (ou não) nessas escolas.

No primeiro capítulo são apresentados os principais conceitos teóricos utilizados e a contextualização do processo metodológico para a análise e interpretação dos dados da pesquisa. Primeiramente, os autores definem o que entendem por política:

[...]será tomado como textos e "coisas" (legislação e estratégias nacionais), mas também como processos discursivos que são complexamente configurados, contextualmente mediados e institucionalmente prestados. A política é feita pelos e para os professores; eles são atores e sujeitos, sujeitos e objetos da política. A política é escrita nos corpos e produz posições específicas dos sujeitos. (op.cit, p. 13).

Isto é a política que, para os autores, é colocada em ação (e não apenas implementada) de diferentes maneiras, pois em cada contexto essa política (ação) demanda diferentes repostas. Nesse sentido, os gestores, os professores e demais funcionários não são meros implementadores da política educacional, ao contrário, eles atuam, reinterpretam, reconfiguram essas políticas de forma mais ou menos criativa; o contexto é que define o processo de atuação. Esse processo, então, é entendido como o espaço de:

\footnotetext{
${ }^{1}$ De acordo com os revisores da obra esse termo é utilizado "no sentido teatral, referindo à noção de que o ator possui um texto que pode ser apresentado/representado de diferentes formas. O texto, no entanto, é apenas uma parte (porém, uma parte importante) da produção. Os autores usam esse termo para indicar que as políticas são interpretadas e materializadas de diferentes e variadas formas. Os atores envolvidos (no caso, os professores) têm o controle do processo e não são "meros implementadores" (op. cit., p. 12)
} 
[...] atuação de política como um aspecto dinâmico e não-linear de todo o complexo que compõe o processo da política, do qual a política é apenas uma parte. Políticas "começam" em pontos diferentes e têm diferentes trajetórias e expectativas de vida; algumas são obrigatórias, outras fortemente recomendadas ou sugeridas. Algumas políticas são formuladas "acima" e outras são produzidas nas escolas ou pelas autoridades locais, ou simplesmente tornam-se abordagens da "moda" na prática sem um início claro. (op. cit., p. 18-19).

Portanto, nesse processo temos que compreender que a política educacional não se restringe apenas às legislações ou suas normatizações. Ela também é encenada, está presente nos corpos, nas ações, nos espaços daqueles que a transformam e a reinterpretam. Dessa forma, "neste livro, o que se entende por política será tomado como textos e "coisas" (legislações e estratégias nacionais), também como processos discursivos que são complexamente configurados, contextualmente mediados e institucionalmente prestados" (op.cit, p. 13). Dessa forma, os autores utilizam-se de teóricos como Foucault, Barthes, Faircolough para compreender a atuação desses atores no processo de transformação dos seus discursos sobre as políticas educacionais.

No segundo capitulo, o foco é compreender os contextos em que essas políticas são atuadas. Os autores aproveitam para fazer uma crítica afirmando que em muitos estudos acadêmicos "a política é desmaterializada" (op.cit, p. 36). Dessa forma, “o material, o estrutural e o relacional precisam ser incorporados na análise de políticas, a fim de compreender melhor atuações das políticas no âmbito institucional” (op. cit, p. 37). Esses contextos são classificados da seguinte maneira: Contexto situado - são abordados aspectos ligados à escola, como matrículas, localização, história etc. Como exemplo da influência desse contexto, são demonstradas situações em que escolas avançam (ou não) nos resultados de exames nacionais, em virtude da seleção (ou não) daqueles que podem realizar a matrícula na escola; Culturas profissionais - que são os valores e o envolvimento dos professores em determinada escola, ou seja, esses elementos serão diferentes para um professor recém chegado, para um professor que trabalha alguns dias da semana naquela escola etc.; são alguns elementos da complexidade nas relações profissionais do ser professor; Contextos materiais - são os aspectos físicos da escola: estado de conservação do prédio, numero de funcionários, materiais pedagógicos, acesso a tecnologias etc.; Contextos externos - são as pressões que a escola sofre, em virtude das políticas, como por exemplo as políticas de 
avaliações externas, em que a pressão por melhores resultados acaba refletindo nas atuações políticas dos atores na escola.

A partir da observação e análise desses contextos teremos a materialidade da política, que é diferente em cada escola. Ou seja, muitas vezes as políticas são pensadas apenas para escolas ditas perfeitas e que não existem na realidade, como afirmam os autores.

No terceiro capitulo é apresentada uma categorização dos atores de políticas que atuam nas escolas. Para essa categorização, dois conceitos são fundamentais: interpretação e tradução. A interpretação é uma decodificação da política, "um processo de explicação, esclarecimento e criação de uma agenda institucional [...] envolve vender a política para a equipe" (op. cit., p. 69). Já a tradução "é um processo interativo de fazer textos institucionais e colocar esses textos em ação, literalmente "atuar" sobre a política" (op. cit., p. 69). Mais adiante, os autores deixam claro como se materializa a tradução, que significa "transformar a política em materiais, práticas, conceitos, procedimentos e orientações” (op. cit., p. 70).

Através desses conceitos temos a seguinte categorização dos atores de políticas (é esclarecido que um ator pode mover-se em diferentes categorias): Narradores - normalmente são os diretores, que têm que fazer um filtro da política, criar uma narração (um discurso), de acordo com o seu contexto, para que a política aconteça. Assim, podem ser utilizadas estratégias de uma política que possibilite unir mais o grupo, motive para que alcancem os resultados, que busque romper como passado da escola etc.; Empreendedores - pessoa carismática, "que se baseia em sua carreira anterior para pensar sobre a educação "de forma diferente" (op. cit., p. 81). Normalmente recombina políticas díspares, reconfigura técnicas, táticas, funções, materiais e apresenta "boas práticas" em que se defende um tipo de atuação política nas escolas, garantindo trazer-lhes avanços; Negociantes - são os membros externos às escolas, fazem parte parceiros, conselheiros, consultores etc. realizam a interpretação e tradução das políticas "vendendo o sucesso da educação"; Entusiastas - são defensores de algumas políticas, e procuram influenciar outros atores, no apoio a estas políticas. Para isso, os entusiastas muitas vezes são tradutores da política, colocando esta em ação através de práticas, materiais, eventos etc.; Críticos - são especialmente os membros dos sindicatos que buscam trazer um contra-discurso sobre as políticas estabelecidas, produzindo (ou não) uma reflexão destas; Receptores - normalmente são os professores e funcionários novatos, que ainda não compreendem os contextos nos quais atuam e acabam consumindo (e defendendo) as interpretações e as traduções das políticas dos atores mais experientes do espaço escolar. 
Após a construção desse quadro de categorização, nos dois capítulos seguintes, os autores passam a analisar a atuação desses atores nas quatro escolas pesquisadas. Para isso são estudadas duas políticas: as de avaliação externa e sobre o comportamento estudantil.

Nas políticas sobre a avaliação externa as escolas são pressionadas para aumentar o padrão de desempenho dos alunos. Assim, escolas, professores e alunos são comparados constantemente por indicadores estabelecidos pelo governo. Para esse processo de pressão, os autores utilizam o termo "deliverogly", desenvolvido por Barber, que consiste em uma cadeia de entrega dos resultados, que vai desde o aluno até a Secretaria do Estado, para se atingir um bom desempenho, o que será necessário para a competitividade econômica global. Nesse processo são estabelecidos mecanismos de coleta de dados, monitoramento, definição de objetivos e metas etc.

Essas táticas resultam em pressão sobre os atores das escolas. Professores e alunos são cobrados para produzirem um bom desempenho, promovendo um modelo de escolaridade que surge a partir de performances e fabricações (BALL, 2010). Esse tipo de política é definido como imperativa, pois não são respeitadas as particularidades das escolas e estabelecidas de forma top-down, onde não existe espaço para interpretações e traduções e "que produzem um sujeito da política principalmente passivo, um "profissional técnico", cuja prática é fortemente determinada pelos requistos de desempenho e entrega, especialmente nas disciplinas de alto risco" (op. cit., p. 131) (aquelas avaliadas nos exames externos, principalmente, línguas e matemática).

Portanto, para atingir esses padrões de desempenho, surge um quase-mercado (BALL, 2014), pois as escolas acabam investindo em diferentes mecanismos para aumentar seus desempenhos, como exemplo: recursos tecnológicos em que escolas, alunos e pais possam acompanhar e monitorar o desempenho destes; empresas de avaliações externas; empresas para acompanhamento e desenvolvimento dos alunos com maiores dificuldades (na Inglaterra os alunos chamados “C/D”) etc ${ }^{2}$. Ou seja, para atingir determinados padrões de desempenho, as escolas acabam canalizando os seus recursos financeiros, pedagógicos, culturais e emocionais somente para tentar melhorar os resultados nos exames externos.

\footnotetext{
${ }^{2}$ No Brasil esse processo vem se estabelecendo nas últimas décadas principalmente com a implantação de várias avaliações externas em larga escala e com o estabelecimento do Índice de Desenvolvimento da Educação Básica. (FREITAS, 2012)
} 
Já em relação às políticas de comportamento, é "solo rico para a investigação de atuações políticas" (op. cit., p. 141). Assim como a política de padrões, as políticas de comportamento também estão diretamente ligadas a um melhor desempenho acadêmico. Entretanto, em relação aos padrões, não existe uma margem para a interpretação e tradução; no tocante ao comportamento esse espaço é muito grande, em especial porque no caso inglês, existe uma série de legislações e normatizações sobre o comportamento nas escolas:

[...] as escolas podem escolher a partir dessa abundância de material aparentemente “pronto para vestir", disponível a partir de agências do estado, voluntárias e privadas. Ou, na verdade, eles podem ignorar tais materiais completamente ao tomar decisões sobre como eles vão atuar ou responder às políticas como a do comportamento par aprendizagem. No entanto, eles não podem escapar de dar uma resposta nesses termos - produzir, revisar e atualizar tanto a sua política de comportamento quanto as práticas que dizem respeito a ela. (op. cit., p. 154)

Isto é, nas políticas de comportamento, as escolas podem atuar com maior liberdade, mas não podem se isentar de realizá-la; essa é grande diferença com as políticas de padrões, a maior autonomia dos atores na atuação dessas políticas. Porém, um ponto em comum entre as duas políticas é que também foi criado um mercado para a melhoria do comportamento dos alunos. Esse negócio, assim como os padrões, é realizado por diferentes empresas, associações etc. Isto porque se estabelece uma relação direta entre bom comportamento e melhor desempenho acadêmico.

Após a análise dessas duas políticas, os autores chamam a atenção no capítulo seis sobre a materialização da política através dos artefatos, que são os materiais visuais e recursos documentais, que circulam nas escolas e poucas vezes são estudados. De acordo com os autores, esses artefatos "marcam o direcionamento da política; que circulam, reforçam e representam o que deve ser feito" (op. cit., p. 172). A partir desse olhar sobre os artefatos no campo da política, são apresentados exemplos de artefatos para a produção de "um bom aluno", como cartazes expostos em uma das escolas estudadas, em que se apresenta de um lado o uniforme adequado para ir à escola e, de outro, as roupas inadequadas; cartazes descrevendo as ações que o aluno precisa realizar para obter a nota mais alta nos exames; cartazes com fotos dos melhores estudantes da semana, e as atitudes que o fizeram merecer esse título. 
Esses artefatos também existem para descrever uma "boa escola"; assim, são utilizados gráficos, tabelas, dados em que se pode ver "a melhoria das escolas". Esses dados significam que os pais podem "literalmente 'ver" melhoria, comparação, desempenho ao longo do tempo, 'ver" o trabalho realizado pela escola no aluno" (op. cit., p. 184). Nesses casos, fica evidente como a "política é representada, interpretada e traduzida - política é encenada" (idem, ibidem).

A imagem do "bom professor" também é refletida nesses gráficos, cartazes, planilhas, dados etc. Ou seja, se a escola atingiu as metas, se o aluno alcançou bons resultados em seu desempenho, significa que temos um bom professor. Portanto, o "bom professor" é aquele que possibilita a seus alunos o alcance de melhores resultados, criando mecanismos e práticas que possibilitem atingir tais resultados.

Obervando esses artefatos os autores fazem uma crítica a essa concepção de educação ao ponderarem que, "em muitos aspectos, nossas escolas parecem estar capturadas por uma versão de educação que está intimamente ligada à escolaridade para competitividade econômica e um crescente abandono ou secundarização (diferentemente na retórica) dos propósitos sociais da educação" (op. cit., p. 185).

Na conclusão inacabada (os autores apontam que a escrita é um momento de escolhas e que muito do que foi pensado, refletido, não fez parte do livro), os autores recuperam a necessidade de que ao estudar as políticas educacionais, é necessário compreender que "as escolas não são uma peça só. Elas são redes precárias de grupos diferentes e sobre postos e pessoas, de artefatos e de práticas” (op. cit., p. 201), e que esses sujeitos políticos não podem ser ignorados. Isso significa que os elaboradores e os pesquisadores de políticas precisam compreender que existe uma escola real, que é complexa e, muitas vezes, contraditória, no processo de construção de suas políticas. Por isso, não existe "um modelo linear de práticas de atuação" (op. cit, p. 197). Cada escola tem o seu contexto que, através da interação contínua entre dados e teoria, precisa ser "levado a sério" nos estudos de políticas, observando os seus próprios discursos, práticas e artefatos que são colocados em ação nesse microespaço social.

Por fim, os assuntos abordados nesse livro são fundamentais para os estudos sobre políticas educacionais. Destaco dois temas: primeiro, pensar que as escolas, através dos sujeitos que lá estão são passivos e incapazes de atuar sobre as políticas é um engano; segundo, as políticas referentes às avaliações e à pressão pela melhoria no desempenho. Atualmente, o Brasil tem balizado suas políticas educacionais por esse caminho; entendemos 
que ficou claro que essa política gera apenas competitividade, desgaste profissional e estresse de pais, alunos e professores. Ou seja, é importante aprender com as experiências de outros países, que nos mostram que essa concepção de educação não possibilita a transformação social, na perspectiva da qualidade social e da valorização das diferenças culturais e sociais.

\section{Referências}

BALL, S. Educação Global S. A.: novas redes de políticas e o imaginário neoliberal. Tradução de Janete Bridon. Ponta Grossa: UEPG, 2014.

Performatividades e fabricações na economia educacional: rumo a uma sociedade performativa. Educação e realidade, v. 35, n. 2, p. 37-55, 2010.

BALL, S. J.; MAGUIRRE, M.; BRAUN, A. Como as escolas fazem as políticas: atuação em escolas secundárias. Ponta Grossa: UEPG, 2016.

FREITAS, L. C. de, et al. Os reformadores empresariais da educação: da desmoralização do magistério à destruição do sistema público de educação. Educação \& Sociedade, v. 33, n. 119, p. 379-404, 2012.

Recebido em: 24/01/2017

Aprovado para publicação em: 23/02/2018

Publicado em: 30/04/2018 